\title{
Hereditary Breast Carcinoma
}

National Cancer Institute

\section{Source}

National Cancer Institute. Hereditary Breast Carcinoma. NCI Thesaurus. Code C4503.

Breast carcinoma that has developed in relatives of patients with history of breast carcinoma. 